hospitals and medical institutions which co-operate very satisfactorily with the public health administration.

The facilities for treatment of trachoma and other eye diseases have been still further developed during the year in close co-operation with the Ophthalmic Hospital of St. John of Jerusalem. Medical Officers of the Government and nurses are trained there and are sent out to various districts to conduct ophthalmic clinics in the government hospitals and dispensaries under supervision. These have been described in previous reports and reviewed in this journal. "Since the inception of the scheme nine medical officers have received training and some of them additional courses. In operative work they perform at least fifty trichiasis operations under supervision and are trained to assist at intraocular operations. They are given a working acquaintance with the prescribing of spectacles, with special reference to the type of case to refer to the visiting surgeon, and with the more obvious conditions demonstrable with the ophthalmoscope. Daily they receive practical instruction in the management of a clinic and the application of treatment. In the devising of this curriculum, especially in the recognition of the imperative need of standardizing operative procedures and methods of treatment, I am indebted to the monumental work of MacCallan in Egypt." The more serious cases at the ophthalmic clinics in the districts are kept for operation by the visiting ophthalmic surgeon from Jerusalem, or if necessary sent to him at the Hospital of St. John. Ophthalmic treatment is given in the schools for trachoma and acute conjunctival diseases by the school nurse or medical orderly by means of drops, and a record of the progress of each case is kept on a special ophthalmic card by the school medical officer. Sixty-nine per cent. of the pupils suffer from trachoma.

\title{
CORRESPONDENCE
}

\section{OCULAR PRESSURES}

To the Editor of The British Journal of Ophthalmology

SIR,-Mr. Duke-Elder has laid us all under great obligation by his discussion of the ocular circulation published in the October number of the Brit. Jl. of Ophthal. particularly for the extensive bibliography which he has furnished.

We have seemingly been trying to measure pressures by different methods, involving different terms and expecting the findings to 
agree; no wonder the result is confusing. Conceding that the ocular constants of two normal individuals of a species are the same, it follows that differences in results of experiments are due to variations in method and that accurately controlled experiments should give constants, in terms of the method used.

The disagreements in results already obtained are perhaps not so hopeless as might at first appear. Taking for instance Mr. Duke-Elder's Table III, which includes extremes, which we know from the premises must be wrong, we find that the average for the systolic pressure is 78 and for the diastolic 41 , figures which do not differ materially from those of 00 and 35 respectively, given by Magitot and Bailliart for a similar method. The mean of these last figures is 46 ; using Donders' estimate, $\mathrm{S}+2 \mathrm{D} . / 3$, a glance at a sphygmographic tracing will show that the formula used in the paper $\mathrm{S}+\mathrm{D} . / 2$ cannot be accurate. This figure of 46 agrees closely with that of 49 , the pressure necessary to stop capillary circulation obtained by Niesnamoff, also by the pressure method.

If the pressure necessary to stop the capillary circulation by means of a manometer in the vitreous chamber were obtained we should have, not capillary pressure, but approximately the threshold pressure at which the system works. We could then form some estimate of the work done by arterial pressure on the one hand and on the other of the amount of buffering in the venous and lymph systems necessary to maintain equilibrium.

There are a number of points connected with the venous and lymph circulations which require detailed study, as for instance the buffering within and without the vorticosae, but discussion of these would be too lengthy.

The transmission of molar fluid through the suspensory ligament in vivo is often taken for granted, but has not, I think, been demonstrated. The point has an important bearing on the action of the lens as an hydraulic ram when tension in the vitreous chamber has been raised.

It should not be difficult to measure ocular pressures in terms of a manometer connected with the vitreous chamber and the error in each case being approximately equal, the relation of the different pressures to each other could be established and the figures used for further work to determine absolute values.

Yours truly,

Richard Kerry.

Montreal.

December 16, 1926. 